\title{
Analysis of different type of transmigrant mandibular teeth
}

\author{
Muhammed-Isa Kara ${ }^{1}$, Sinan Ay ${ }^{2}$, Ali-Murat Aktan ${ }^{3}$, Ismail Şener ${ }^{4}$, Cihan Bereket ${ }^{4}$, Şeref Ezirganlı ${ }^{5}$ \\ Mehmet Demirkol ${ }^{6}$
}

\author{
${ }^{1}$ Assistant Professor, Department of Oral and Maxillofacial Surgery, Gaziantep University, Faculty of Dentistry, Gaziantep, \\ Turkey \\ ${ }^{2}$ DDS, PhD, Associate Professor Department of Oral and Maxillofacial Surgery, Gaziantep University, Faculty of Dentistry, \\ Gaziantep, Turkey \\ ${ }^{3}$ DDS, PhD, Assistant Professor Department of Oral Diagnosis and Radiology, Gaziantep University, Faculty of Dentistry, Ga- \\ ziantep, Turkey \\ ${ }^{4}$ DDS, PhD, Assistant Professor Department of Oral and Maxillofacial Surgery, Ondokuz Mayıs University, Faculty of Dentis- \\ try, Samsun, Turkey \\ ${ }^{5}$ DDS, Research Assistant, Department of Oral and Maxillofacial Surgery, Cumhuriyet University, Faculty of Dentistry, Sivas, \\ Turkey \\ ${ }^{6}$ DDS, Research Assistant, Department of Oral and Maxillofacial Surgery, Gaziantep University, Faculty of Dentistry, Sivas, \\ Turkey
}

Correspondence:

Gaziantep University Faculty of Dentistry

27310, Gaziantep, Turkey

phismer@yahoo.com

\author{
Isa-Kara M, Ay S, Murat-Aktan A, Sener I, Bereket C, Ezirganli S, \\ Demirkol M. Analysis of different type of transmigrant mandibular teeth. \\ Med Oral Patol Oral Cir Bucal. 2011 May 1;16 (3):e335-40. \\ http://www.medicinaoral.com/medoralfree01/v16i3/medoralv16i3p335.pdf

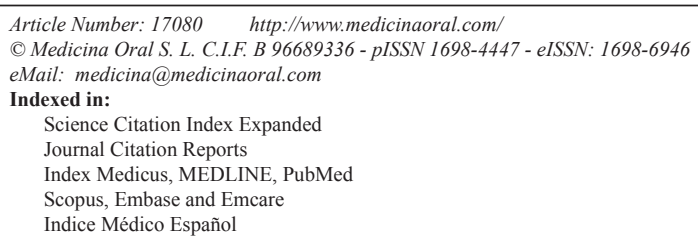

\begin{abstract}
Objective: Until recently, most reports about transmigration have documented that the canine is the only tooth which can migrate to the opposite side of the arch. The goal of the study was to define the transmigration of different types of teeth in people in various regions of Turkey.

Study Design: A total of 112,873 panoramic radiographic files from seven different Turkish cities were inspected. The following data were evaluated according to age, gender, number of transmigrant teeth, localization, eruption status, side, unilaterally or bilaterally and associated pathology or dental abnormalities.

Results: Of the 112,873 radiographs included in the study, 90 were seen to present as transmigrant in 87 patients, representing $0.079 \%$ of the sample. There were only two $(0.0017 \%)$ transmigrant lateral (TML) teeth and only three $(0.0026 \%)$ transmigrant premolar (TMP) teeth encountered. The mean age at the time that the transmigrant mandibular teeth were identified was 29.9 years, with a range from 10 to 66 years. Out of the 87 cases, 51 were female and 36 were male, with a male:female ratio of 1:1.41. Transmigrants were more commonly seen unilaterally $(96.5 \%)$. The most frequent associated pathology was odontoma.

Conclusions: Because early detection is vital to prevent complications and ensure more successful treatment, these extensive studies are crucial. In this extensive study, we indicated cases of transmigration of premolar and lateral teeth as a variant. Demographic variables and properties of all transmigrants (TM) were also presented.
\end{abstract}

Key words: Transmigrant teeth, panoramic radiography, mandible. 


\section{Introduction}

Impacted mandibulary teeth are encountered relatively rarely (1). It is an even more unusual condition when such impacted mandibulary teeth move to the opposite side of the arch, across the mandibular midline. This abnormal movement of a tooth is known as dental transmigration $(2,3)$.

The exact mechanism of transmigration is not yet known, and there are many hypotheses about it. Transmigration is more often encountered in females than in males, and most often unilateral and symptomless. They can appear at any age and ranged from 8 to 62 years (4).

Many authors (5-7) are concerned with the classification and the incidence of impacted teeth, specifically premolars, and the decreasing ratio of canine and lateral teeth. Although failure of eruption of the mandibulary canine and lateral is an unusual event, impaction of the mandibular second premolar is most often seen, accounting for $23 \%$ of all impactions excluding third molars, with an overall frequency of impaction of $0.1 \%$ (5).

It is not an extraordinary phenomenon that eruption anomalies may influence different types of teeth. One problem regarding the eruption procedure is that it is logically anticipated to influence all teeth to a different degree, because there are the same mechanisms of eruption of different teeth due to the actions of various genes (8). Until recently, almost all reports on transmigration have documented that the canine is the only tooth in which migration and crossing of the midline. But recently, Camilleri (8) has reported transmigration of a lateral incisor case, and Alves (9) has reported a transmigration of a premolar case. However, there is only one case report and no study including these transmigrated teeth. In this extensive study, we present results which exhibit transmigrations of premolars and laterals. Canine transplantations are also presented.

In this study we aimed to determine the occurrence of other types of transmigrated teeth. For this purpose, we presented a specific and extensive study, which included 112,873 individuals, considering transmigrated premolar, lateral and canine teeth. It also evaluated incidence and demographic variables of transmigrant teeth and discussed etiology and behavior of transmigration.

\section{Materials and Methods}

The study was undertaken with an initial sample of 112,873 subjects drawn from the orthopantographic image files of nine clinics in seven different cities in Turkey. Data were collected from the central (Sivas, Kayseri, Tokat, and Konya), western (Bolu), northern (Samsun), and southern (Gaziantep) regions of Turkey. Diagnoses of TM teeth were made during radiographic evaluations in all cities. Radiographic examination of the molar region was based on panoramic radiographs independently by five dentists with over five years of experience.

For each patient we collected demographic variables, including the number of transmigrated teeth, age, and gender. Following the radiographic examination, we analyzed the characteristics of the TM, including location, eruption status, side, unilaterally or bilaterally. Retained deciduous teeth and associated pathology or dental abnormality were also evaluated. Regarding localization, TM teeth were classified according to Mupparapu (10). Because no studies were found including TML and TMP, classifications of these teeth were made according to Mupparapu's (10) TM canine classification. Additionally, localizations were also evaluated where the insizal cusp of a tooth arrived in the opposite side of the dental arch.

\section{Results}

\section{-Demographic data}

Of the 112,873 radiographs included in the study, 90 were seen to present TM in 87 patients, representing $0.079 \%$ of the global sample. The distribution of mandibular TMs according to different regions of Turkey is shown in table 1 . There were only two $(0.0017 \%)$ TML (Fig. 1) and only three (0.0026\%) TMP (Fig. 2a, b) teeth encountered. The mean age at the time that the transmigrant mandibular teeth were identified was 29.9 years, with a minimum age of 10 years and a maximum age of 66 years. The mean age of patients was 32 for the TMP teeth group, and 45 for the LTM teeth group. We found 36 males and 51 females subjects, with a male:female ratio of 1:1.41 (Table 2). Two patients who had TMP were female and the other was male. One of the patients with an LTM tooth was female and the other was male. -Eruption status

Regarding their status within the arch, the great majority (97.8\%) of mandibular TM were impacted, and only $2.2 \%$ had erupted (Table 2). All of the TML and TMP teeth were impacted. Each of the erupted TM teeth was classified as a type 5 canine tooth. Other types of mandibular TM teeth were impacted.

\section{- Classification}

According to Muppurappu's (10) classification, type 1 was the major type of all mandibular TM teeth and accounted for $47.7 \%$ of all cases, followed by type 2 (25.5\%), type $5(12.2 \%)$, type $4(9.9 \%)$ and type $3(4.4 \%)$ (Table 2,3). The classification of one TML tooth and all TMP teeth was type 2 . The other type of TML was type 1.

\section{-Location}

$50(55.5 \%)$ of the mandibular TM teeth were located on the right side and $40(44.4 \%)$ TM teeth were located on the left.

Most of the incisal cusps of the TMs (30\%) were located in the line of the opposite side of the lateral inci- 


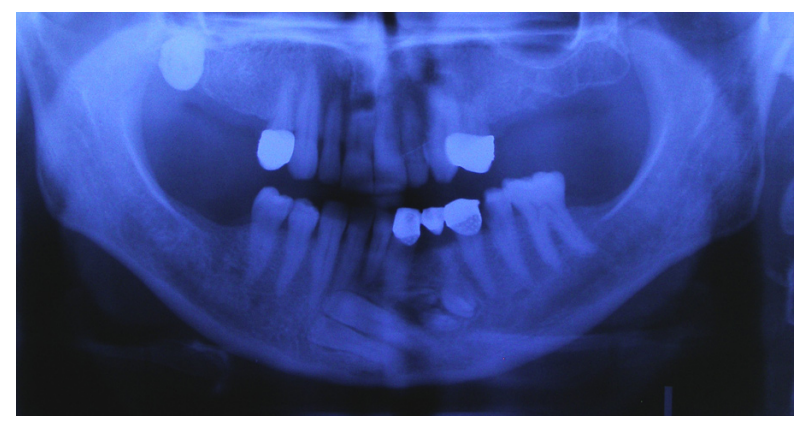

Fig. 1. Panoramic radiography showing transmigrant mandibular left canine and lateral incisor. Note the odontomas in the left canine area.

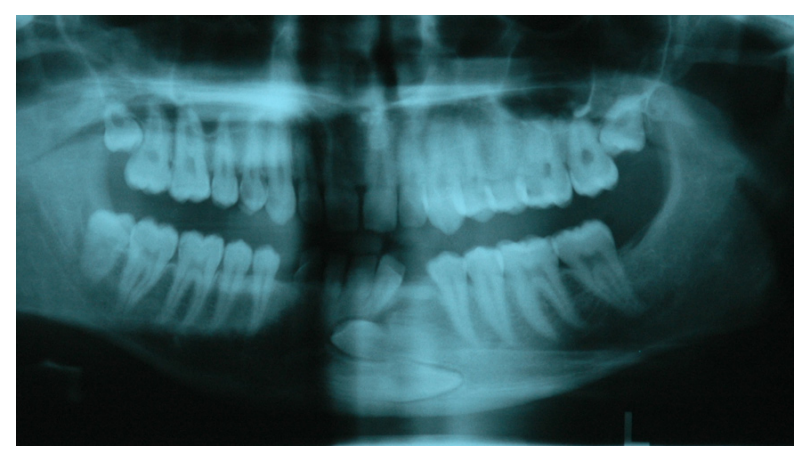

Fig. 3. Radiographic appearance of bilateral transmigrant teeth.

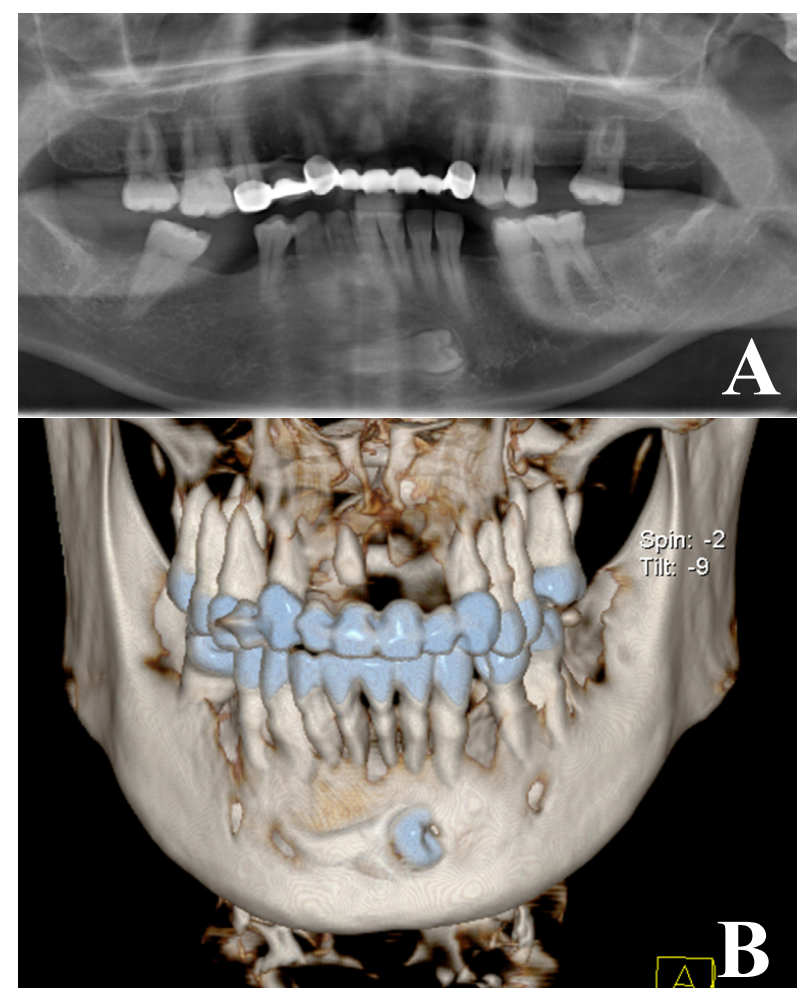

Fig. 2. A) Panoramic radiography appearance of transmigrant mandibular right second premolar. B) Computerized tomography appearance of transmigrant mandibular second premolar.

Table 1. Distribution of mandibular transmigrant teeth according to different location of Turkey.

\begin{tabular}{|c|c|c|c|c|c|c|c|c|c|}
\hline \multicolumn{10}{|c|}{ Transmigrant Teeth } \\
\hline & n & Lateral & $\%$ & Canine & $\%$ & Premolar & $\%$ & Total TM & $\%$ \\
\hline Bolu & 3049 & - & - & 3 & 0.01 & - & - & 3 & 0.01 \\
\hline Tokat & 1960 & - & - & - & - & - & - & - & - \\
\hline Kayseri & 11858 & - & - & 6 & 0.05 & 1 & 0.008 & 7 & 0.059 \\
\hline Konya & 67458 & 1 & 0.0014 & 50 & 0.07 & 1 & 0.001 & 52 & 0.077 \\
\hline Gaziantep & 14295 & - & - & 10 & 0.07 & 1 & 0.007 & 11 & 0.076 \\
\hline Samsun & 6500 & - & - & 2 & 0.03 & - & - & 2 & 0.03 \\
\hline Sivas & 7753 & 1 & 0.0012 & 14 & 0.18 & - & - & 15 & 0.193 \\
\hline Total & 112873 & 2 & 0.0017 & 85 & 0.075 & 3 & 0.0026 & 90 & 0.079 \\
\hline
\end{tabular}

Table 2. Relation between type, gender and eruption status of transmigrant teeth.

\begin{tabular}{|l|c|c|c|c|c|}
\hline & \multicolumn{2}{|c|}{ Male } & \multicolumn{2}{c|}{ Female } & \\
\hline & Impacted & Erupted & Impacted & Erupted & Total \\
\hline Type 1 & $16(17.7 \%)$ & - & $27(30 \%)$ & - & $43(47.7 \%)$ \\
\hline Type 2 & $5(5.5 \%)$ & - & $18(20 \%)$ & - & $23(25.5 \%)$ \\
\hline Type 3 & $3(3.3 \%)$ & - & $1(1.1 \%)$ & - & $4(4.4 \%)$ \\
\hline Type 4 & $6(6.6 \%)$ & - & $3(3.3 \%)$ & - & $9(10 \%)$ \\
\hline Type 5 & $7(7.7 \%)$ & $1(1.1 \%)$ & $2(2.2 \%)$ & $1(1.1 \%)$ & $11(12.2 \%)$ \\
\hline Total & $37(41.1 \%)$ & $1(1.1 \%)$ & $51(56.6 \%)$ & $1(1.1 \%)$ & $90(100 \%)$ \\
\hline
\end{tabular}


Table 3. Location of mandibular transmigrant teeth in the jaw.

\begin{tabular}{|c|c|c|c|c|c|c|c|c|}
\hline \multicolumn{10}{|c|}{ Transmigrant teeth } \\
\hline & Midline & $\begin{array}{c}\text { Central } \\
\text { incisor }\end{array}$ & $\begin{array}{c}\text { Lateral } \\
\text { incisor }\end{array}$ & Canine & $\begin{array}{c}1 . \text { Premo- } \\
\text { lar }\end{array}$ & $\begin{array}{c}2 . \text { Premo- } \\
\text { lar }\end{array}$ & 2. Molar & Total \\
\hline Type 1 & $8(8.8 \%)$ & $9(9.9 \%)$ & $17(18.8 \%)$ & $9(9.9 \%)$ & - & - & - & $43(47.7 \%)$ \\
\hline Type 2 & $3(3.3 \%)$ & $3(3.3 \%)$ & $7(7.7 \%)$ & $10(11.1 \%)$ & - & - & - & $23(25.5 \%)$ \\
\hline Type 3 & - & $1(1.1 \%)$ & $3(3.3 \%)$ & - & - & - & - & $4(4.4 \%)$ \\
\hline Type 4 & - & - & - & - & $5(5.5 \%)$ & $3(3.3 \%)$ & $1(1.1 \%)$ & $9(9.9 \%)$ \\
\hline Type 5 & $11(12.2 \%)$ & - & - & - & - & - & - & $11(12.2 \%)$ \\
\hline Total & $22(24.4 \%)$ & $13(14.4 \%)$ & $27(30 \%)$ & $19(21.1 \%)$ & $5(5.5 \%)$ & $3(3.3 \%)$ & $1(1.1 \%)$ & $90(100 \%)$ \\
\hline
\end{tabular}

sor tooth. $24.4 \%$ were located in the midline and $21.1 \%$ were located in the line of the canine tooth. The other locations were shown in table 3 .

Of the 87 patients whose TM radiographs we examined, a unilateral distribution was found in 84 (96.5\%) patients, while two (2.3\%) exhibited a bilateral distribution (Fig. 3). Additionally only one (1.15\%) double mandibular TM was observed.

\section{-Pathology and dental abnormalities}

The main associated pathologies of mandibular TM were odontoma (four patients), followed by follicular or cystic differentiation (three patients).

Considering dental abnormalities associated with mandibular TMs, impacted third molar teeth was the most common seen (29 teeth in 16 patients); followed by impacted canine (13 teeth in 12 patients), lateral and canine tooth translation (six patients); missing mandibular second premolar (four teeth in two patients), missing maxillary lateral incisor (three teeth in three patients) and a fourth molar (one tooth).

Furthermore, 41 patients had retained deciduous canines, and the remainder (49 patients) had exfoliated deciduous canines.

\section{Discussion}

The etiology of transmigration still remains unclear, although numerous theories exist in the literature to explain their occurrence. Most authors point to mesioanguler and horizontal rotation of buds as an etiologic factor for transmigration. It has also been suggested that transmigrants are a result of an abnormal strong force of eruption $(11,12)$. Moreover, in the case of tumors, cysts and odontomas, in which an entity is blocking teeth's paths of eruption, early loss of primary teeth, retention of the primary canine, crowding, spacing and supernumerary teeth were shown as possible factors (5). Formerly, transmigration was described as physiological migration of unerupted teeth across the midline in the absence of any pathological entity. But, because there was no consensus whether pathological entities were responsible for the transmigration of the teeth or not, and teeth that were associated with dentigerous cysts and odontomas and passed through the midline were accepted as transmigrations (11). In this study, transmigration cases influenced by different pathologies like cysts or odontomas were included. In this study, four odontoma cases and three cyst cases were accompanied by TM.

The mandibular lateral incisor may sometimes be displaced, but it more commonly finds its way into the oral cavity. Existence of physical barriers such as retained primary teeth, odontomas or severe crowding can cause this abnormality. The lateral tooth almost migrates to the distal side of the jaws and is generally encountered on the right side and unilaterally (13). In the present study, only two cases of TML were demonstrated in 112,873 radiographs with a percentage of $0.0017 \%$. Camilleri's (8) report, a double transmigration case, which is the single case of transmigration of a lateral tooth, has been reported unilaterally and originated from the left side of the jaw. In this study, an extremely rare case of double transmigration with transmigration of a mandibular canine and the lateral incisor was also presented. This case was similar to Camilleri's (8) report, which was unilateral and caused by double teeth which originated from the left side of the jaw. However, the difference in this case was that odontomas were most likely the possible cause of transmigrations.

It was accepted that the essential cause of canine migration is generally related to genetic reasons, but the principal causes of migration of premolars are idiopathic or casual (9). The initial angulation of the tooth and early loss of the decidious mandibular molars is important for distal migration of mandibular premolars (14). The mandibular second premolar may be distally inclined in an oblique or horizontal position, because of the variable degree of the initial distal angulations of the developing tooth bud under the distal root of the primary second molar. Early resorption of the primary second molar's root and permanent first molar can lead to distal migration of the second premolar tooth (14). 
Although the premolars are the most commonly migrated teeth, transmigration of these teeth are an extremely rare condition. In the literature, there was only one case (9) which reported a transmigrated premolar tooth. In the present study, only three cases were encountered with a percentage of $0.0026 \%$. Migrations of premolars are commonly seen in females, with a male to female ratio of 1:2, which corroborates our study.

The incidence of canine transmigration was also uncommon. According to Javid (15), only one transmigrated canine was revealed in 1,000 students. In a 4,000 patient series, Zvolanek (16) did not encounter any cases. Considering the Turkish subpopulation in the case of TMs, they are observed in $0.31 \%$ according to Aydin et al. (11), in $0.34 \%$ according to Aktan et al. (7) and in $0.33 \%$ according to Büyükkurt et al. (17). Canine transmigration was found in 0.075 percentages in our study, which do not corroborate these studies. These differences may be explained due to the fact that the sample of other Turkish studies was obtained at university hospitals which treat patients that already have some type of jaw disease, and thus may not represent the real frequency of the general population.

Eruption of transmigrated teeth is a rare condition, which occurs in approximately $5 \%$ of cases, as reported in the literature (4). Similarly, bilateral transmigration is also a most unusual phenomenon. Büyükkurt et al. (17) did not report any bilateral transmigration in their report. Joshi (18) reported four bilateral TM of 28 patients in his report. In this study, only $2.2 \%$ of mandibular TMs were erupted and only $2.3 \%$ of patients with TMs were bilateral. Additionally, a double transmigration as described is obviously most uncommon, and to our knowledge only one case (9) has been previously reported in the literature.

In this study, there was a slight overall female predominance, with a male to female ratio of 1:1.41. Although this finding corroborates with most reports, $(2,7,12)$ the sex distribution reported by some authors (17) showed a higher frequency among males.

The classification based on the migration pattern and final position of mandibulary canine transmigrants was asserted by Mupparapu (10): Type 1 for a canine impacted mesio-angularly across the midline, labial or lingual to the anterior teeth; Type 2 for a canine horizontally impacted near the inferior border of the mandible inferior to the apices of the incisors; Type 3 for a canine erupting on the opposite side of the jaw; Type 4 for a canine horizontally impacted near the inferior border of the contralateral side and Type 5 regardless of eruption status, canine positioned vertically in the midline with the long axis of the tooth crossing the midline.

According to Mupparapu (10), the most frequently encountered type of transmigrant teeth was type 1 , followed by type 2 and then type 4 . Type 5 was the least frequently seen. Büyükkurt et al. (17) also reported that type 1 was the most common type, followed by type 3 , type 2 , type 5 and type 4 . In this study, type 1 (47.7\%) was the most common type, which coincides with these reports, but in contrast, type 3 is the less common type and constituted only $4.4 \%$ of all mandibular transmigrants. Type 2 , type 5 , and type 4 constituted $25.5 \%$, $12.2 \%$ and $9.9 \%$ of all mandibular transmigrants, respectively. Considering TMP, all of them were type 2, which coincides with Alves et al. (9) report. One of the TML was type 2, which corroborates Camilleri's (8) report, and the other was type 1 .

Early detection and appropriate intervention can prevent the possible future complications caused by the transmigrated teeth. Therefore, clinical evaluation followed by a detailed radiographic screening is vital to achieve an accurate diagnosis of these teeth and optimal management. In addition, management will depend on transmigrant location, and whether or not clinical complications. Treatment may be surgical or the patient may be followed up without surgical intervention. Exposure and orthodontic alignment or transplantation can also be considered as a treatment option (19).

\section{Conclusions}

It has been speculated, and almost taken as a fact in most reports, that transmigration does not affect any other dental group other than canines. In literature, there is little and limited knowledge about the presence of transmigrations of lateral or premolar teeth. For this reason, in this extensive study we aimed to declare cases of transmigration of premolar and lateral teeth as a variant.

\section{References}

References with links to Crossref - DOI

1. Ozan F, Kara I, Ay S. Impacted mandibular permanent incisors associated with a supernumerary tooth: a case report. Eur J Dent. 2009;3:324-8.

2. Joshi MR. Transmigrant mandibular canines: a record of 28 cases and a retrospective review of the literature. Angle Orthod. 2001;71:12-22.

3. Aras MH, Büyükkurt MC, Yolcu U, Ertaş U, Dayi E. Transmigrant maxillary canines. Oral Surg Oral Med Oral Pathol Oral Radiol Endod. 2008; 105:e48-52.

4. Torres-Lagares D, Flores-Ruiz R, Infante-Cossío P, García-Calderón M, Gutiérrez-Pérez JL. Transmigration of impacted lower canine. Case report and review of literature. Med Oral Patol Oral Cir Bucal. 2006;11:E171-4.

5. Camilleri S, Scerri E. Transmigration of mandibular canines--a review of the literature and a report of five cases. Angle Orthod. 2003;73:753-62.

6. Vuchkova J, Farah CS. Canine transmigration: comprehensive literature review and report of 4 new Australian cases. Oral Surg Oral Med Oral Pathol Oral Radiol Endod. 2010;109:e46-53.

7. Aktan AM, Kara S, Akgünlü F, Malkoç S. The incidence of canine transmigration and tooth impaction in a Turkish subpopulation. Eur J Orthod. 2010;32:575-81.

8. Camilleri S. Double transmigration and hyperdontia. Angle Orthod. 2007;77:742-4.

9. Alves DB, Pedrosa EF, Andreo JC, de Carvalho IM, Rodrigues Ade 
C. Transmigration of mandibular second premolar in a patient with cleft lip and palate--case report. J Appl Oral Sci. 2008;16:360-3.

10. Mupparapu M. Patterns of intra-osseous transmigration and ectopic eruption of mandibular canines: review of literature and report of nine additional cases. Dentomaxillofac Radiol. 2002;31:355-60.

11. Aydin U, Yilmaz HH, Yildirim D. Incidence of canine impaction and transmigration in a patient population. Dentomaxillofac Radiol. 2004;33:164-9.

12. Aktan AM, Kara S, Akgunlu F, Isman E, Malkoc S. Unusual cases of the transmigrated mandibular canines: report of 4 cases. Eur J Dent. 2008;2:122-6.

13. Shapira Y, Kuftinec MM. The ectopically erupted mandibular lateral incisor. Am J Orthod. 1982;82:426-9.

14. Shapira Y, Kuftinec MM. Intrabony migration of impacted teeth. Angle Orthod. 2003;73:738-43.

15. Javid B. Transmigration of impacted mandibular cuspids. Int J Oral Surg. $1985 ; 14: 547-9$.

16. Zvolanek JW. Transmigration of an impacted mandibular canine. Ill Dent J. 1986;55:86-7.

17.Büyükkurt MC, Aras MH, Caglaroglu M, Gungormus M. Transmigrant mandibular canines. J Oral Maxillofac Surg. 2007;65:2025-9.

18. Joshi MR, Daruwala NR, Ahuja HC. Bilateral transmigration of mandibular canines. Br J Orthod. 1982;9:57-8.

19. Al-Waheidi EM. Transmigration of unerupted mandibular canines: a literature review and a report of five cases. Quintessence Int. 1996;27:27-31. 